\title{
Curcumin Ag nanoconjugates for improved therapeutic effects in cancer
}

This article was published in the following Dove Press journal:

International Journal of Nanomedicine

\section{Darshini Shah \\ Reema Savaliya \\ Pal Patel \\ Krupa Kansara \\ Alok Pandya \\ Alok Dhawan \\ Sanjay Singh}

Institute of Life Sciences, School of Science and Technology, Ahmedabad University, Ahmedabad, Gujarat, India
Correspondence: Sanjay Singh Institute of Life Sciences, School of Science and Technology, Ahmedabad University, Navrangpura, Ahmedabad, Gujarat 380009, India Email sanjay.singh@ahduni.edu.in

\begin{abstract}
Curcumin has a broad spectrum of pharmacological activities, one of them is anticancer activity that is mediated through multiple mechanisms. The major disadvantage associated with the use of curcumin is its low bioavailability due to its poor aqueous solubility. Nanoformulations of curcumin provide an effective solution for this problem. In this study, we have synthesized curcumin Ag nanoconjugates and evaluated their anticancer potential.
\end{abstract}

Keywords: curcumin, anticancer, nanoconjugate, AgNPs

\section{Introduction}

The major challenge faced by modern scientific and medical research is the need to develop new anticancer treatments with greater efficacy and fewer side effects. ${ }^{1}$ Natural products have been widely used by our ancestors to combat illness, and that trend has been growing over the past few decades. Current medicines have been revolutionary in curing diseases, but their harmful side effects have led to the use of natural products. Curcumin is one of the many natural products containing such beneficiary properties. Curcumin is a polyphenol derived from Curcuma longa plant, commonly known as turmeric. Curcumin has been used extensively in Ayurvedic medicine for centuries, as it is nontoxic and has a variety of therapeutic properties including antioxidant, analgesic, anti-inflammatory, and antiseptic activities. ${ }^{2}$ Recently, curcumin has been shown to possess anticancer activities through its effect on a variety of biological pathways. It has not been clinically used yet, due to its sparing solubility in water and low bioavailability. Various studies have reported that the bioavailability of curcumin could be increased by conjugating it with metal nanoparticles (NPs). Hence, in this study, we have made an attempt to synthesize AgNPs functionalized by curcumin and analyze its anticancer properties. The effects of curcumin-reduced AgNPs (C-AgNPs), L-tyrosine-reduced AgNPs (T-AgNPs), and free curcumin on the viability of human epidermoid carcinoma cell line (A431 cells) was compared.

\section{Materials and methods Curcumin AgNPs synthesis}

C-AgNPs were synthesized using the method described by Bettini et al with slight modifications. ${ }^{3}$ Briefly, $\mathrm{AgNO}_{3}\left(10^{-3} \mathrm{M}\right)$ was mixed with $10^{-5} \mathrm{M}$ curcumin solution. The $\mathrm{pH}$ was adjusted to 9 using $1 \mathrm{M} \mathrm{NaOH}$, and the solution was allowed to boil until the color changed to orangish yellow.

\section{Synthesis of T-AgNPs}

T-AgNPs were synthesized using the method described by Selvakannan et al with slight modifications. ${ }^{4}$ Briefly, $\mathrm{AgNO}_{3}\left(10^{-3} \mathrm{M}\right)$ solution was mixed with $10^{-3} \mathrm{M}$ aqueous 
solution of L-tyrosine in 1:1 ratio. The $\mathrm{pH}$ was adjusted to 10 using $1 \mathrm{M} \mathrm{NaOH}$, and this solution was allowed to boil until the color changed to yellow.

\section{Characterization of AgNPs}

C-AgNPs and T-AgNPs were dialyzed for $24 \mathrm{~h}$ by $12 \mathrm{kDa}$ dialysis bag against the copious amount of deionized water. This removed the unreduced ions of $\mathrm{Ag}$ and other reaction products, which might have formed during the NPs synthesis. Dialysis also decreased the $\mathrm{pH}(\sim 7)$ of NPs suspension, which was alkaline $(>9)$ as required by NPs synthesis. Hydrodynamic size and zeta potential of C-AgNPs and T-AgNPs were determined using Zetasizer Nano-ZS, and absorbance spectrum was determined using UV-visible spectrophotometer (Synergy HT multi-mode microplate reader).

\section{Cell viability assessment}

The effects of curcumin, C-AgNPs, and T-AgNPs was determined using 3-(4,5-dimethylthiazol-2-yl)-2,5 diphenyltetrazolium bromide (MTT) assay on A431 cell line. ${ }^{5}$ A431 cells were commercially purchased from the National Center for Cell Sciences, Pune, India.

\section{Results and discussion}

The hydrodynamic size and zeta potential of C-AgNPs and T-AgNPs were found to be $29.0 \pm 0.10,-27 \pm 2.30$ and $41.72 \pm 0.21,-30.0 \pm 0.66$, respectively (Table 1 ). The synthesized AgNP solutions were stable for more than a month. High zeta potential value further supports the high stability of AgNP solutions.

The UV-visible absorbance (Figure 1) spectrum of $\mathrm{C}$-AgNPs and T-AgNPs along with their respective controls was recorded as shown in Figure 1. The maximum absorbance of C-AgNPs was found to be $420 \mathrm{~nm}$, and it coincides with that of T-AgNPs, indicating that AgNPs have been successfully synthesized. Other solutions such as curcumin, $\mathrm{AgNO}_{3}-\mathrm{NaOH}$, curcumin- $\mathrm{AgNO}_{3}$, and curcumin- $\mathrm{NaOH}$ after extensive boiling showed absorbance

Table I Hydrodynamic size and zeta potential of C-AgNPs and T-AgNPs

\begin{tabular}{lll}
\hline Characteristics & Nanoparticles & \\
\cline { 2 - 3 } & C-AgNPs & T-AgNPs \\
\hline Hydrodynamic size (d. nm) & $29.0 \pm 0.10$ & $41.72 \pm 0.21$ \\
Zeta potential $(\mathrm{mV})$ & $-27.7 \pm 2.30$ & $-30.0 \pm 0.66$ \\
PDI & $0.25 \pm 0.002$ & $0.22 \pm 0.009$ \\
\hline
\end{tabular}

Note: Data presented as mean \pm SD.

Abbreviations: C-AgNPs, curcumin-reduced AgNPs; PDI, polydispersity index; T-AgNPs, L-tyrosine-reduced AgNPs.
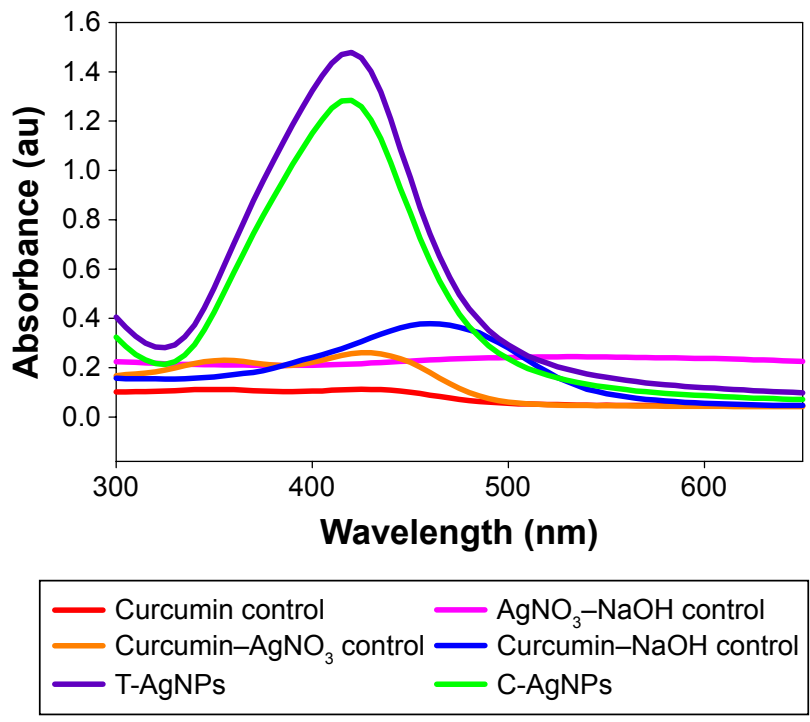

Figure I UV-visible spectrum of C-AgNPs and T-AgNPs along with controls. Abbreviations: C-AgNPs, curcumin-reduced AgNPs; T-AgNPs, L-tyrosine-reduced AgNPs.

at $425 \mathrm{~nm}, 530 \mathrm{~nm}, 425 \mathrm{~nm}$, and $460 \mathrm{~nm}$. However, as clearly evident in Figure 1, the absorbance intensity of these solutions was found to be very weak and did not match with the absorbance of AgNPs.

Human skin carcinoma cells (A431) were exposed to different concentrations of free curcumin, T-AgNPs, and C-AgNPs for $24 \mathrm{~h}$, and cell viability was determined using MTT assay. Here, curcumin concentration corresponds to the amount of curcumin required to synthesize 40 and $60 \mu \mathrm{g} / \mathrm{mL}$ of C-AgNPs (Figure 2). Free curcumin showed only marginal decrease in cell viability. However, T-AgNPs showed a concentration-dependent decrease in cell viability ranging

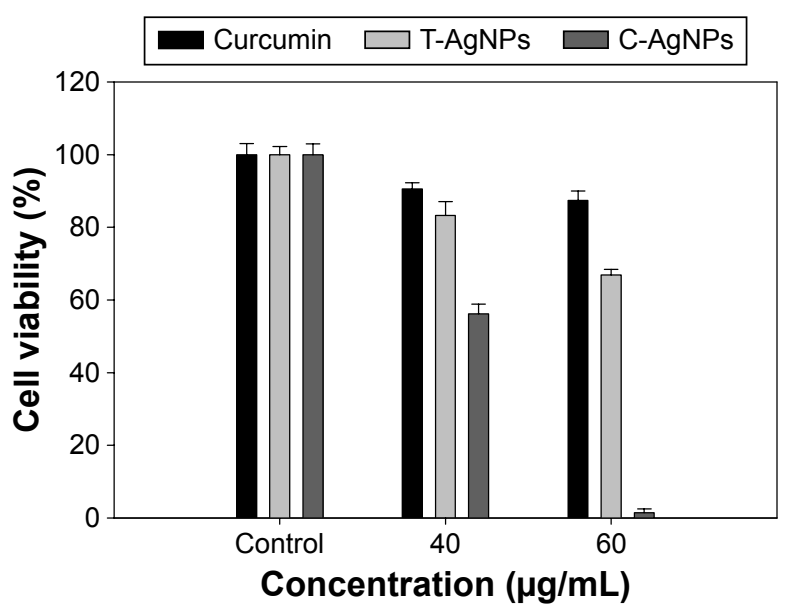

Figure 2 Cell viability assessment of curcumin, T-AgNPs, and C-AgNPs on A43I cells. Abbreviations: C-AgNPs, curcumin-reduced AgNPs; T-AgNPs, L-tyrosine-reduced AgNPs. 
from $20 \%$ (at $40 \mu \mathrm{g} / \mathrm{mL}$ ) to $37 \%$ (at $60 \mu \mathrm{g} / \mathrm{mL}$ ). However, exposure to C-AgNPs leads to significant reduction in cell viability ranging from $44 \%$ to $98.5 \%$ at 40 and $60 \mu \mathrm{g} / \mathrm{mL}$ concentrations, respectively (Figure 2). This observation suggests that the synergistic anticancer effect of curcumin and AgNPs leads to cell death in A431 cells.

\section{Conclusion}

C-AgNPs and T-AgNPs are found to be toxic to the skin carcinoma (A431) cells than free curcumin at higher concentration $(60 \mu \mathrm{g} / \mathrm{mL})$. Promising anticancer activity of C-AgNPs suggests its potential to be used as a chemotherapeutic agent for cancer treatment.

\section{Acknowledgments}

The authors gratefully acknowledge the Centre for Nanotechnology Research and Applications (CENTRA) by The Gujarat Institute for Chemical Technology (GICT). RS would like to thank the University Grant Commission (UGC),
New Delhi, for the award of Junior Research Fellowship. The manuscript contains ILS-manuscript No 045.

\section{Disclosure}

The authors report no conflicts of interest in this work.

\section{References}

1. Salem M, Rohani S, Gillies ER. Curcumin, a promising anti-cancer therapeutic: a review of its chemical properties, bioactivity and approaches to cancer cell delivery. RSC Advances. 2014;4(21):10815-10829.

2. Wilken R, Veena MS, Wang MB, Srivatsan ES. Curcumin: a review of anti-cancer properties and therapeutic activity in head and neck squamous cell carcinoma. Mol Cancer. 2011;10(12):1-19.

3. Bettini S, Pagano R, Valli L, Giancane G. Drastic nickel ion removal from aqueous solution by curcumin-capped Ag nanoparticles. Nanoscale. 2014;6(17):101-113.

4. Selvakannan PR, Swami A, Srisathiyanarayanan D, et al. Synthesis of aqueous Au core-Ag shell nanoparticles using tyrosine as a pH-dependent reducing agent and assembling phase-transferred silver nanoparticles at the air-water interface. Langmuir. 2004;20(18):7825-7836.

5. Mosmann T. Rapid colorimetric assay for cellular growth and survival: application to proliferate and cytotoxicity assays. J Immunol Methods. 1983;65(1-2):55-63.
International Journal of Nanomedicine

\section{Publish your work in this journal}

The International Journal of Nanomedicine is an international, peerreviewed journal focusing on the application of nanotechnology in diagnostics, therapeutics, and drug delivery systems throughout the biomedical field. This journal is indexed on PubMed Central, MedLine, CAS, SciSearch ${ }^{\circledR}$, Current Contents ${ }^{\circledR} /$ Clinical Medicine,

\section{Dovepress}

Journal Citation Reports/Science Edition, EMBase, Scopus and the Elsevier Bibliographic databases. The manuscript management system is completely online and includes a very quick and fair peer-review system, which is all easy to use. Visit http://www.dovepress.com/ testimonials.php to read real quotes from published authors. 